\title{
Leadership to advance data and information science at Virginia Tech library
}

\author{
Julie Griffin ${ }^{\mathrm{a}, \mathrm{b}, *}$ \\ ${ }^{a}$ Associate Dean for Research \& Informatics, University Libraries, Virginia Polytechnic Institute and \\ State University, Blacksburg, VA 24060, USA \\ ${ }^{\mathrm{b}}$ Senior Associate Dean, University Libraries, Virginia Polytechnic Institute and State University, \\ Blacksburg, VA 24060, USA
}

\begin{abstract}
Libraries have adapted and are continuing to adapt to the rapidly changing information and data needs of the communities they support. The following paper presents the evolution of Virginia Tech University Libraries, with special attention given to program and service developments in data and information science. The author describes leadership strategies for advancing services, shares stories about developing sustainable, human-centered, and technology-enhanced service infrastructures, and paints a picture of aspirations to enable individuals' success through active campus engagement. The paper will end with an overview of challenges and opportunities for future collaboration within higher education and beyond.
\end{abstract}

Keywords: Data science, information science, libraries, leadership

\section{Introduction}

University library services necessarily adapt to constituents' changing needs, which are impacted to a growing degree by transdisciplinary approaches, the drive to use data to address technical and societal problems, the inherent desire to make sense of - and derive meaning from-data, and by the influence of commercial data and information services and products on user expectations. Libraries vary in their response to these and other changes, including the degree to which they engage their local and campus communities in the change process, the degree to which they learn together and from each other, and the emphasis placed on leadership, specifically change leadership. The following paper will describe how a community of the Virginia Tech Libraries has responded to changing user needs in the ways described in order to position their library faculty, staff, and students for success in data and information science.

Dumas and Beinecke [1, p. 867] describe effective change leaders as individuals who, "encourage their organizations to learn, innovate, experiment, and question." This description of leadership as an intentional cultivation of organizational curiosity resonates with me as an associate dean overseeing Research, Learning and Informatics (RL\&I) programs at Virginia Tech Library, where change is and has been a constant due to developments in practice at the professional and library levels. However, as we know, developments impacting libraries extend beyond the walls of the information profession.

\footnotetext{
*E-mail: gjulie@vt.edu.
} 
In 2015, Virginia Tech launched a Beyond Boundaries visioning process [2], which included, among other areas of emphasis, a focus on advancing the university's existing research strengths, expanding the university's global land grant mission, and helping people develop both disciplinary knowledge and transdisciplinary experiences. Data and decision sciences emerged as one of nine transdisciplinary strengths of the university.

\section{Community \& Leadership}

During this time of change, the Libraries had been for several years developing new services and infrastructures to support open access, open education [3], digital scholarship, data management and analytics [4,5], digital curation, and research collaboration and impact. Our new services and collaboration interests began to align nicely with opportunities presented during Beyond Boundaries conversations. The question became how we would simultaneously achieve our goals to advance library services and also engage with partners to realize the university's more expansive vision.

University Libraries are, and have been for some time, a highly engaged organization within the larger academic enterprise at Virginia Tech. Our community engagement dates back to a program established in 1994 that reimagined the role of liaison as embedded partner and service provider for the colleges [5]. Over the last several years, however, the Libraries have increased both the volume of credit-bearing courses taught and the vigorous pursuit of external funding for research projects. In both cases our involvement is often in cross-disciplinary collaborations. We serve as senior investigators and co-principal investigators on grants with other faculty, co-teach credit bearing courses with other faculty, co-author papers with other faculty, and serve as co-directors and associate directors of labs and centers established by or based in other departments, and this is in addition to conducting our own research and directing our own research center. These activities represent an increase in partnerships as colleagues and peers in the teaching and research process.

When I joined the organization a few years before the Beyond Boundaries vision was established, with a strong foundation and culture of partnership and innovation to build upon, my focus was given to reimagining the role of the library through connected infrastructures, multi-year cluster hiring to expand our areas of internal consulting expertise and service, and change leadership to ensure successful new program outcomes and retention of diverse talent and expertise. A specific example of an effort to connect university infrastructures and to expand services would be an initiative to connect the libraries' open access repository, VTechWorks [6], to the university's electronic faculty activity reporting system. The initiative represents a cross-campus partnership with the Office of the Executive Vice President and Provost, as well as with the Virginia Tech Division of Information Technology and the Office of Research and Innovation.

Through this partnership, we took an established library service and experimented with embedding the repository service in an existing faculty workflow to increase adoption of open access practices. Over time, the role of the Libraries' in supporting the university's research information ecosystem expanded from being provider of open access archiving services to becoming partner-provider of a suite of researcher services, including research impact, researcher identifiers, researcher profiles, research analytics, metadata, and open access services. We took intentional steps to expand our support for faculty success by experimenting with new roles, adopting new frameworks for presenting our services, and developing and sustaining new university partnerships.

The partnerships we sustained in this case, as well as in most other cases, manifest as active crosslibrary and cross-campus teams, and are characterized by an alignment with our values, a desire to make a 
positive impact and to support our users, as well as to, in the case of our services, leverage interoperability standards to enable data use and reuse. Another example includes our partnership with faculty in the department of computer science to develop digital library infrastructure to support data reuse [7].

Working effectively in teams is critical in this kind of dynamic, highly networked and partnershipbased environment. I encourage individuals in RL\&I to share work, roles, and leadership as needed, and to support each other when necessary to strengthen the impact of our contributions. I practice modeling collaboration and leadership practices that emphasize support, inclusiveness, sharing, and teamwork. With department directors, I distribute a community-wide email newsletter with notes of thanks and recognition of achievements and contributions. I encourage individual and group participation as much as possible, for example, inviting RL\&I community members to name the new community, to develop the community's mission, vision, and values statements and to plan and lead retreats and team building workshops. I try to respond to expressions of interest in leadership, create opportunities, and adjust my role in projects as needed. All of these activities are designed to establish connections for individuals across seemingly disparate concepts, services, and activities.

The successful translation of potentially conflicting individual-level campus engagement and programlevel goals into a thriving community of people providing a diverse set of services to an expanding university comes down to four leadership activities: (1) listening and being open to new ideas and suggestions, (2) creating a culture of distributed thought leadership, (3) leading community towardsand creating space to find-commonality across activities and programs, (4) celebrating and respecting different interests, approaches, strategies, and perspectives; and (5) supporting creativity through learning and experimentation.

\section{Learning \& service philosophy}

What guides my leadership philosophy is a desire to advance creativity, innovation, and research education at the university by helping people and teams establish fruitful connections. Through these connections, whether made via access to library services, learning spaces, resources, experiences, or information and data science talent, my hope is that individuals and teams are able to develop new and deeper knowledge, to contextualize experiences, to engage in community, to share in the celebration of achievements, to identify potential in themselves and others, and to practice leadership.

When we do these well and when we support others in doing these well, I believe we see positive outcomes. At the university or community level, this translates to success in academics and research, more impactful scholarship, and a more adaptable organization. We also see demonstrated thinking and engaging beyond disciplinary and methodological boundaries, which all leads to greater success in data and information science.

In terms of how the Libraries help to connect the individual experience with community-level outcomes, we develop individuals' develop digital literacy skills [8], provide value added data and information services, and leverage our talents and skill sets to help people, whether in a role as facilitator, data analyst, designer, scholar, research partner, or curator. We do what we have always done well, the only difference is that in a technology-enriched environment we choose to take an even more user- and human- centered approach to our work.

The frameworks through which individuals can engage with our services (e.g. through use of spaces and services, and through partnerships in research and scholarship) are focused on providing personalized experiences as much as possible. The common theme across frameworks and engagement opportunities 
is a focus on applying to the best of our ability our data and information science knowledge and talents to advance research and scholarship. We do this best when we can help users make connections across services and service models. Establishing connections can take the form of referrals, co-consulting, joint programs within the library and across campus, and through services aimed at helping users succeed in collaboration and transdisciplinarity. While many of our services are offered as campus-wide support, increasingly our focus on longitudinal impact has us involved as partners in projects. We approach scaling these efforts in different ways: hiring and cross-training to develop capacity to reach a larger number of faculty, staff, and students; collaborating and sharing responsibility (as previously mentioned); and developing service partnerships. I encourage exploration of all of the above at different levels of effort for different services as part of the change process.

Learning is key to preparing for the opportunities presented by data and information science. The process of learning, perhaps most importantly, will help us understand how our skills, expertise, and priorities need to evolve. To deepen learning engagement we must give ourselves time to explore new ideas, to take risks, and learn together and with the communities we support. As part of this process, we need to practice the competencies and skills that we strive to help others develop and seek out learning opportunities that help to contextualize our experiences, and assist others in doing the same. All of these types of learning experiences contribute to a more understanding community and adaptable service organization.

Active partnerships are also critically important for success. Libraries are undergoing a similar kind of change as other academic units. It would make sense, for example, for us to explore with our campus partners how we measure success in a transdisciplinary, highly collaborative, rapidly evolving, partnership-based environment. Because data is an important part of the storytelling process, we should bring our data expertise to bear when working with partners to find ways to cultivate a data way of thinking and working, and carefully consider privacy and ethics issues with data collection, management, use, and sharing.

Designing services and developing partnerships to support teams is also important. We need to work with others to develop infrastructures that help community members address and overcome problems. We do this by designing and implementing change frameworks when needed, and by supporting the change frameworks designed and implemented by community members. We should pursue partnerships that reinforce our global land grant mission, including international research partnerships and library exchange programs. And, as a land grant institution library, we need to partner to increase public engagement, make education more affordable, and make our experiences and services more accessible to all.

To move forward requires changing the way we work and interact, creative approaches to problem solving, and empathetic leadership. If we explore all of the above within our libraries and with partners in/outside of our institution, we are advancing data and information science.

\section{Conclusion}

In a Beyond Boundaries library that advances data and information science, we must be able to make connections and empower others to make connections across disciplines, communities, organizations, and the world. By removing traditional barriers in the provision of services, the RL\&I community practices making the scholarly record more open, facilitates transdisciplinarity, practices upholding our professional values and ideals to promote "equitable access to information" [9], and integrates services to facilitate the institutional stewardship — and future use and reuse — of content. We also strive to enable connections 
that facilitate beyond boundaries through adaptive leadership approaches, collaborative learning, and partnership-based services. It is my belief that in doing so, we position the Libraries for success in enabling members of the VT community to effectively leverage data and information to make a positive impact in the world now and into the future.

\section{Acknowledgements}

All of University Libraries have helped to shape my leadership approach and philosophy. I would like to thank the leadership team in RL\&I for directing the programs described in the paper, including open access, open education, publishing, data, teaching and learning engagement, digital literacy, digital collections, digital preservation, immersive environments, and learning environments, and also the RL\&I community for delivering programs and services and engaging directly with library users.

\section{About the Author}

Julie Griffin, University Libraries senior associate dean, leads a team of individuals offering faculty, staff, and students at Virginia Tech unique research education opportunities, experiences, and connections across a diverse portfolio of information and data services. Phone: +1 (540) 231 7193; Email Address: gjulie@vt.edu.

\section{References}

[1] C. Dumas and R. H. Beinecke, Change leadership in the 21st century, Journal of Organizational Change Management 31(4) (2018), 867-876, Available from: doi:10.1108/JOCM-02-2017-0042.

[2] R. Bleizner, A. Grant and T. Rikakis, Envisioning Virginia Tech Beyond Boundaries: A 2047 Vision. Retrieved from: http://hdl.handle.net/10919/79633 (Accessed May 21, 2019).

[3] A. Walz, Open and editable: Exploring library engagement in open educational resource adoption, adaptation and authoring, Virginia Libraries 61: (2015), 3-31, Retrieved from: http://hdl.handle.net/10919/52377 (Accessed May 28, 2019).

[4] A.L. Ogier, A.M. Brown, J. Petters, A. Hilal and N. Porter, Enhancing collaboration across the research ecosystem: using libraries as hubs for discipline-specific data experts, in: Proceedings of the Practice and Experience on Advanced Research Computing (PEARC '18). ACM, New York, NY, USA. Available from: doi: 10.1145/3219104.3219126.

[5] N.H. Seamans and P. Metz, Virginia Tech's innovative college librarian program, College \& Research Libraries 63(4) (2002), Available from: doi:10.5860/crl.63.4.324.

[6] VTechWorks is Virginia Tech's institutional repository available at https://vtechworks.lib.vt.edu.

[7] Z. Xie and E. Fox, Advancing library cyberinfrastructure for big data sharing and reuse, Information Services and Use 37(3) (2017), 319-323, doi:10.3233/ISU-170853. Available at: https://content.iospress.com/download/information-services-anduse/isu853?id=information-services-and-use\%2Fisu853 (Accessed June 15, 2019).

[8] J. Feerrar, Literacies \& campus context: leading the campus conversation, in: Proceedings of the Innovative Library Classroom, TILC 2018, May 8-9, 2018, Radford, Virginia, USA. Retrieved from: http://hdl.handle.net/10919/83379, (Accessed May 28, 2019).

[9] American Library Association's Core Values, Key Action Areas and Strategic Directions. Retrieved from: http://www. ala.org/aboutala/, (Accessed February 8, 2019). 